\title{
IN-VISÍVEIS: novas táticas de militância artística
}

IN-VISIBLES: some new strategies in art and activism

\section{Alessandra Vannucci}

Alessandra Vannucci Professora de Direção Teatral, na graduação, e de Processos Criativos, no Programa de Pós-Graduação em Artes da Cena

(PPGAC), da ECO-UFRJ

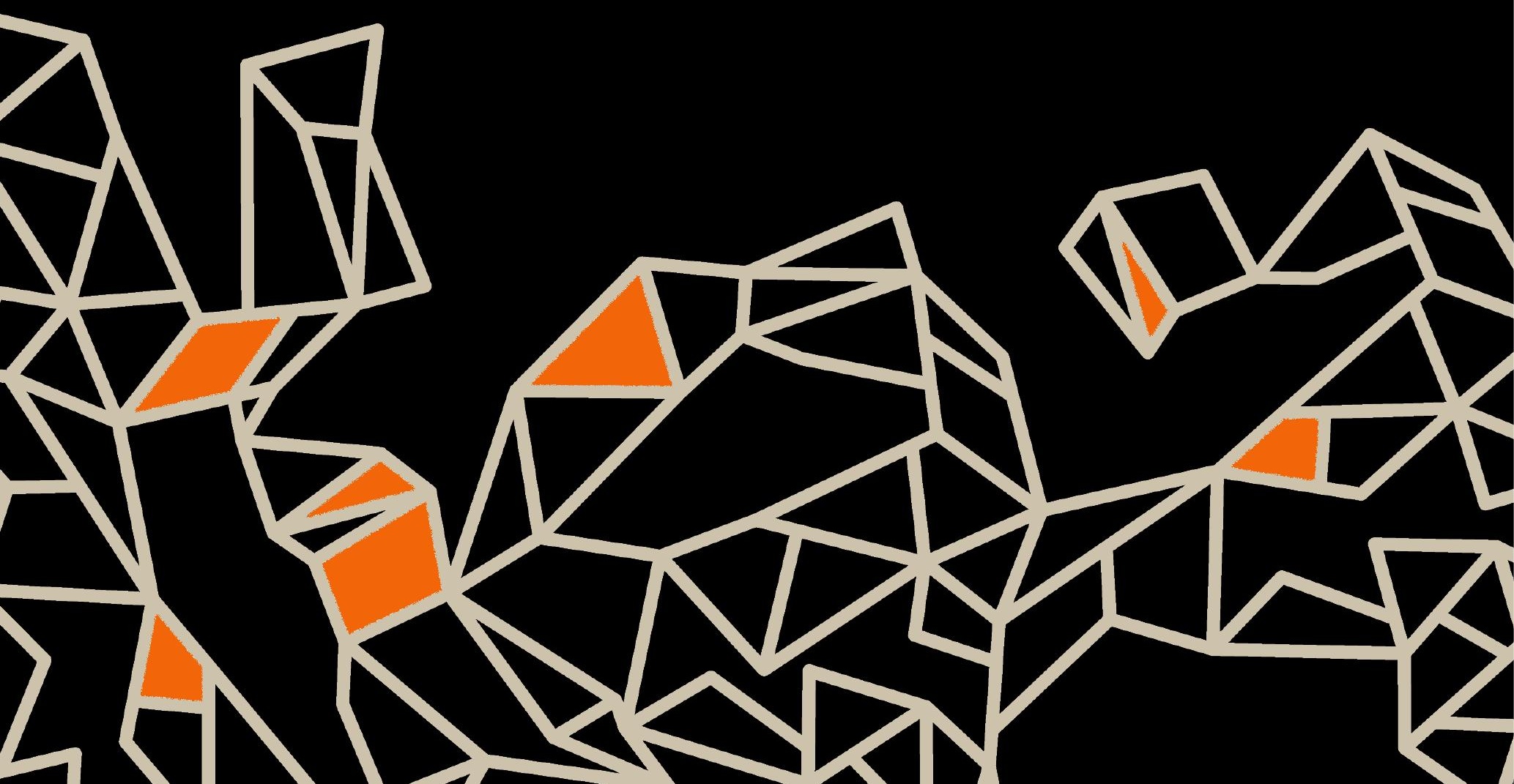




\section{Resumo}

No imaginário contemporâneo, o futuroé prefigurado mais frequentemente como uma distopia - marcada por condições de opressão, vigilância, privação - do que como formas utópicas que estimulavam a imaginação modernista. Aqui refletimos acerca da arte como dispositivo de resistência: quais táticas podem pôr em disputa os modos da vida em comum e modificá-los. Analisamos um acervo experimental de gestos estético-políticos (intervenções, instalações, performances site-specific) elaborados em grupo aberto de pesquisa artístico-acadêmica. Pode a arte destacar-se como ação de militância em nossas cidades-espetáculo saturadas por mídias normativas das condutas cotidianas? Como tais gestos podem deslocar as expectativas representacionais canônicas e inaugurar contra condutas na comunidade de espect-atores?

Palavras-chave: Cena expandida, Novos regimes estéticos, Função do espectador.

\section{Abstract}

In the contemporary imaginary, our common future is prefigured more often as a dystopia - life in extreme conditions of oppression, vigilance, deprivation - than as the utopian forms that stimulated the modernist imagination. Here, we discuss whether art may work as a device of resistance at this awful perspective: which artistic gestures are capable of challenging our ways of life and modifying them. We analysed an experimental collection of aesthetic-political gestures such as urban interventions, happenings, installations and site-specific acts based on displacement that we designate under the sign of artivism developed in an open group of artistic-academic research. How can art stand out as an act of resistance in our "societé du spectacle" saturated by a normative media that controls our everyday conducts? How such experiences of urban art may displace the conventional actor-spectator expectations and introduce counter-conducts in the representational system?

Keywords: Expanded field of arts, New aesthetic regimes, Spectator's roles. 
Este ensaio apresenta reflexos do processo criativo compartilhado por um grupo transdisciplinar de pesquisa ${ }^{1}$ composto por discentes, docentes, artistas e cidadãos cada qual trazendo ideias e práticas de diversas disciplinas de especialização e de vivências cotidianas. Durante três anos, no Rio de Janeiro, o grupo elaborou táticas performativas focadas na intervenção direta do pensamento estético no espaço público; a cada semana, realizávamos "saídas" que constituíam experimentos práticos indissolúveis do debate teórico que as alimentava. $\mathrm{O}$ anseio de fazer transitar a pesquisa entre academia e cidade ampliou perspectivas; sob o lema do "artivismo" (ativismo por meio da arte, ver LEMOINE, 2010), empreendemos ações extensionistas visando ativar outras comunidades criativas. Em 2013, acompanhando as manifestações de junho e sua representação nos meios de comunicação por imagens formatadas e legendadas com vistas a distribuir significados e responsáveis de modo premeditado, nos perguntamos se e como poderíamos manter nossa ação estético-política fora do alcance de tal dispositivo disciplinar. Uma primeira estratégia foi postar na rede as nossas "saídas" sem indicação de crédito, a não ser a ambígua assinatura INVISÍVEIS. Além disso, nos questionamos como poderíamos fazer funcionar nossas ações como contra dispositivos e antídotos a tal colonização do imaginário. Como entrar com nossos corpos na disputa entre regimes de visibilidade em ato na cidade?

Elegemos a escrita complexa, combinatória e visionária de Cidades invisíveis, de Italo Calvino, como uma forma capaz de resgatar poeticamente as cidades censuradas, removidas e esquecidas cujas cicatrizes marcam a superfície da nossa, interessada por uma previsão iminente de mudanças arquitetônicas radicais² ${ }^{2}$ Dessa forma, surgiu a intervenção urbana Invisíveis.

Imaginem um viajante que narra ao Kublai Kan, imperador dos Tártaros, as riquezas das cidades que o Império conquistou. Não encontra outra forma a não ser contar o que cada cidade teria de único e se tornou

1 Grupo de estudos em Estética e Política da pós-graduação em Literatura, Cultura e Contemporaneidade da PUC-Rio, confluído em 2014, no Laboratório de Estética e Política da ECO-UFRJ. O coletivo (apoiado pela FAPERJ nas modalidades APQ1, APQ2, Grupos Emergentes e Apoio à Produção Artística) realiza encontros semanais e intervenções de arte pública, cursos de extensão com multiplicações formativas, seminários (Artivismo e Utopia, PUC-Rio 2014) e publicações. A presente pesquisa é apoiada pelo CNPq.

2 Obras de fim de mandato do prefeito Eduardo Paes (PMDB), reunidas sob os lemas de Cidade olímpica e Porto maravilha. 
invisível, uma vez que foi submetida aos desenhos imperiais. Como escravas de um vasto harém, as cidades ocultam sua verdadeira essência sob o véu de nomes femininos. Os nomes são emblemas da possibilidade perdida de ser; traços dos afetos proibidos, dos desejos interditados, da imaginação assassinada; são cicatrizes, memória de vida guardada nas pedras. Cada cidade afeta o viajante pelo que emana do passado que um dia foi um destino possível, uma possibilidade de futuro. Daqui a evocação de cidades tristes, sensuais, cidades de nuvens e de filigranas, cidades do céu estrelado ou enterradas no lixo, cidades possíveis que os desenhos imperiais ordenam, subjugam e aniquilam. Elas não se adaptam à paisagem real: a reescrevem, mas só por um instante, num piscar de cílios. ${ }^{3}$

Desenvolvemos essa sinopse em um mapa de ocupação adaptável a cada praça, conforme rotas determinadas pelo imperador Kublai, interpretado por um ator em trajes de morador de rua, carregando em um carrinho de supermercado todo o sistema de amplificação, filmagem e contrarregragem. Cada cidade é interpretada por um ator que a escolheu, no texto de Calvino, como forma sintomática de sua relação afetiva com a cidade em que vivemos; não são personagens, mas instalações humanas, cada qual delimitando no ambiente da praça seu espaço praticável, designado de "bólide" (estrutura desmontável) ou "tapete" (remarcação do chão). A andança aleatória do imperador-mendigo "liga" cada instalação de modo que, só quando por ele é tocada, inicia seu texto e sua partitura, enquanto as outras se mantém em uma dimensão de inoperosidade que consiste na presença potencial de algo que pode vir a acontecer. As instalações aparecem no regime clandestino da piratagem, seja porque sua execução não é autorizada, seja porque contrabandeiam figuras da história da arte; são "repertório do potencial, do hipotético, de tudo que não é, nem foi, mas que poderia ter sido,' conforme sugere o próprio Calvino (1990, p. 106). São percebidas como comportamentos estranhos. Em vez de imobilizar o imaginário dos transeuntes na contemplação de uma cena verossímil mesmo que ficcional, mobilizam-no por serem excêntricos, extrapolando os afetos normalmente consentidos. Ao mesmo tempo, ocupando espaços úteis e interferindo no fluxo contínuo das mercadorias, as

3 Sinopse da peça, que estreou em 2014, no Largo do Machado, e foi replicada em outras "praças" reais e simbólicas do Rio de Janeiro, como a Cinelândia, o Pilotis da PUC-Rio e o Campus da ECO/UFRJ. 
instalações são corpos estranhos que suspendem a disciplina das rotas e das condutas urbanas, friccionando desejos cristalizados entre corpos e revelando proibições normatizadas. No vocabulário situacionista da década de 1970, seriam táticas psicogeográficas de "deriva", ou seja, dimensões perceptivas inesperadas e efêmeras que se sobrepõem ao real e o contaminam, expondo seus avessos numa cartografia poética que reescreve a paisagem urbana. $\mathrm{O}$ objetivo de tais epifanias é embaraçar o regime de visibilidade, funcionando como bolhas em que o transeunte porventura se adentra.

\section{Reescrever a cidade}

Nas Propostas para o próximo milênio, Calvino propõe a "visibilidade" entre as táticas que gostaria de remeter como legado vade-mécum para o mundo futuro, diante da "perda de forma" que constata no presente. Bombardeados, como somos, por "mil estilhaços de imagens pré-fabricadas, como em um depósito de lixo, onde é cada vez menos provável que uma delas adquira relevo" (p. 107), nos perguntamos como salvar a imaginação individual - a que Calvino chama de "fantasia", ao modo dos magos renascentistas, isto é, uma certa participação do sujeito criador na alma do mundo. O autor avança duas propostas: "reciclar as imagens usadas, inserindo-as em um novo contexto que lhes mude o significado" ou, então, "apagar tudo e começar tudo do zero" (p. 111). A primeira ideia provocaria estranhamento e maravilha; a segunda (como no caso de Samuel Beckett, por meio da redução ao mínimo dos elementos visuais e da linguagem) induziria o espectador à experiência da subjetivação da catástrofe - a sensação de estar "em um mundo depois do fim do mundo" (p. 111). Como afetar o transeunte sem que ele se torne imediatamente consumidor de mais um produto artístico ou promocional? Como atingir sua fantasia?

Reciclando figuras anacrônicas e incôngruas, ora pelo tema (uma vênus nua no trânsito, uma bailarina na mesa de xadrez, uma modelo deitada no lixo), ora pelo tempo (um coro lentíssimo que atravessa a praça, um ser coberto de lama que se arrasta rápido entre as pernas das pessoas), ora pelo gesto (um carregador de cadáveres, um leitor de classificados que espalha seu jornal no chão, um trabalhador que desenrola uma centena de metros de 
cabo elétrico pela praça), as instalações humanas de Invisíveis procuram maravilhar o transeunte, alterar seu estado de espírito e sua trajetória, sem impor-Ihe um conteúdo consumível - mensagem exposta ou normativa. Embora subjetivadas pelo comportamento intensamente performático dos atores, que ali expressam seus afetos, as instalações permanecem anônimas; tal contradição, sugerindo uma experiência ambígua de visão, induz o transeunte a elaborar suas próprias falas sobre como aquele comportamento estranho perturba a normalidade e, possivelmente, a levantar questionamentos sobre sua própria sujeição às normas impostas pelo sistema disciplinar que rege nossa vida. Há uma potência fantasmagórica e, ao mesmo tempo, real na andança do imperador-mendigo (Kublai) em que se soma à fala cifrada do imperador a verborragia agressiva do mendigo: é uma alucinação ancestral e uma presença óbvia na praça, emblema de nossa condição de cotidiana catástrofe. Sua voz contamina o espaço sonoro do lugar e insiste para ser ouvida, resistindo à invisibilidade em que o empurramos; como outros moradores de rua, ele lê o ambiente, decifra os acontecimentos, denuncia o que está omitido, dramatiza a insegurança e provoca atrito, desnaturalizando o familiar até para quem passa por ali todos os dias. Kublai é um flanêur. É o baudelairiano "cão do tempo" que inesperadamente reorganiza o sentido do lugar, revelando cicatrizes no corpo da cidade, marcos da violência arquitetônica e midiática com que desejos e imaginações individuais são submetidos ao desenho hegemônico. Sua leitura livre de qualquer lógica dependente do capital expõe o esqueleto da sociedade espetacular que a todos inclui. Ele diz (recolhendo a fala do Marco Polo que conclui o livro de Calvino):

O inferno dos vivos não é algo que será. É o que já temos aqui, que habitamos todo dia, que produzimos convivendo. Há duas maneiras de não sofrer. A primeira, muitos escolhem: aceitar o inferno, entrar a fazer parte dele até não mais vê-lo. A outra é arriscada: buscar o que, no meio do inferno, não é inferno e abrir-lhe espaço e fazer com que dure.

A praça é um hábitat carregado de presença, seus bancos, balcões, cantos são lugares "comuns" no sentido que selam a existência de uma ou mais comunidades de pessoas com seus afetos, memórias, utopias, frustrações e opressões. No entanto, é preciso admitir que o mapa da metrópole 
não corresponde mais à ocupação por parte dos cidadãos, cada qual com sua classe e função, de ruas e prédios conforme a gestão do bem comum, como na cidade medieval, moderna e modernista. Sinais de trânsito preponderam na cena urbana contemporânea, implicando em coerções e barragens que visam a mobilidade de bens e mercadoria e limitam, paradoxalmente, acessibilidade e convivência entre pessoas. Em algum caso, a cidade é inteiramente alienada do uso dos cidadãos tendo seu aproveitamento projetado na dimensão de futuro cartão postal, não correspondente à cidade real. Sob o lema "estamos trabalhando para vocês" que normalmente acompanha tais imagens, representando a separação entre quem atua e quem contempla, um ambíguo conceito patriótico vela a proibição de usufruto do bem comum. Cabe questionar o que é "comum" nas novas tramas urbanas, onde a formação de fluxos livres de cidadãos e de novas comunidades, mesmo que transitórias (como nas manifestações), está sujeita a permanente controle e interditada por barragens impostas pelos inúmeros sistemas de vigilância e pela arquitetura. Assim, a cidade não atende aos modos de vida, mas dispõe sobre eles ditando normas de conduta, trajes convenientes e castigos devidos para cada infração, deliberando sobre o que pode ser visto e o que deve ser in-visibilizado - é o que Kublai reconhece como "o inferno que produzimos convivendo" (apud CALVINO, 1970).

As bolhas constituídas pelas instalações constituem frestas perceptivas que interrompem e se sobrepõem àquele regime de visibilidade - projetam, sobre o real paginado, outros espaços em que cidadãos reescrevem a cidade, apesar e contra aquelas normas. Assim como as derivas situacionistas e outras "zonas autônomas temporárias" (ver HAKIM BEY, 1969), tais como navios piratas e bordéis, batizadas por Foucault de heterotopias, tais bolhas são "espaços ilusórios que denunciam como mais ilusório qualquer espaço real e todos os posicionamentos nos quais a vida humana é compartimentalizada" (2009, p. 420). Sua dimensão teatral (no sentido mais literal da palavra teatron: lugar do olhar e do ser olhado) não é incompatível, mas alternativa e resistente ao regime representativo que governa a sociedade espetacular pela separação entre artistas e espectadores, dos quais se espera serem meros consumidores daquilo que é exibido e imposto (DEBORD, 1967). Na comunidade estética temporária, os corpos percebem-se expostos (veem-se 
uns aos outros), como território em disputa, entre normas urbanas e fantasias "anormais", vida civilizada e vida "nua", ou seja, não domesticada e por isso, in-visibilizada. Ao invés que acomodar-se no papel de espectador-consumidor, o transeunte percebe a si mesmo como ator-produtor, seja daquela instalação-bolha na qual penetrou, seja da estrutura maior que é a cidade-espetáculo: percebe que compartilha a escrita daquela cena, obedecendo ou enfrentando e modificando as qualidades dos afetos entre corpos e cidade. Reescrever não significa escrever de novo, mas escrever em cima, sobre, junto. É, como sugere Kublai, "buscar o que, no meio do inferno, não é inferno e abrir-lhe espaço e fazer com que dure" (apud CALVINO, 1970).

\section{Táticas de contágio}

Nossa intervenção resultou da necessidade de buscar táticas para infiltrar o espetáculo totalmente preenchido da cidade e irromper no "comum" ordenado pelas técnicas de produção sociocultural, entre as quais as artes. Como não ser redundante com mais um espetáculo na sociedade do espetáculo? Como não ser mais um produto descartável onde tudo é descartável? Como destacar uma ação de resistência às lógicas de consumo entre as inúmeras ações voltadas para estimular o mais amplo consumo? Preocupa (ver CANCLINI, 1997) a perda de forma de eventos como, por exemplo, o carnaval, já happening popular incubador de subjetivação e de ativismo político e agora máquina de desejos colonizada pela hegemonia dos agentes da representação que ali replicam suas formas exclusivas (cordões, blocos). Por ter noção de que o teatro, como gênero, retrata a segregação do "comum" - não só pela separação entre artistas e espectadores visíveis em seus edifícios, como também pela separação entre arte e vida que embasa o sistema representativo -, buscamos em nossas instalações não reproduzir tal segregação no espaço público. Atentando para o fato de que todo movimento ideológico adquire formas estéticas e maneiras de fazer que agregam o próprio conteúdo político do movimento, buscamos inventar táticas inconformadas aos mecanismos de controle e que funcionem como antídotos a tais mecanismos (DE CERTEAU, 1998, p. 41). Como aponta Walter Benjamin (1985, p. 129-146), é tarefa dos artistas não somente multiplicar os meios de produção 
como também re-funcionalizar as formas, de modo que sejam eficazes para mudança de percepção dos agentes de processos culturais. Como fazer que o transeunte perceba a si mesmo como ator-produtor e não mais como mero espectador-consumidor da situação proposta pela obra no quadro amplo da cidade-espetáculo em que é inserida?

Uma primeira tática dissolve a distância que separa palco e plateia, seja a distância física, seja a da distinção de funções entre quem atua e quem assiste, que configura não somente a maioria dos edifícios teatrais como também, em muitos casos, o teatro na rua e outras manifestações públicas (por exemplo, paradas militares, comícios e vitrines) interessadas em produzir expectativas de contemplação e consumo. Trata-se de propor formas que alterem a disciplina passiva implícita na função de espectador e que intensifiquem a presença do transeunte como alguém incluído na produção ficcional dos acontecimentos da praça, a par dos atores, não imediatamente reconhecíveis como personagens (caso de algumas modalidades do Teatro do Oprimido, por exemplo, o Teatro Invisível). Por si só, a condição de atuar na rua, local já totalmente ocupado pelo deslocamento de corpos e mercadorias cujo fluxo não pode ser facilmente interrompido, obriga a negociar a disponibilidade de espaços - muros, palácios e postes como eventual pano de fundo com fonte de carga elétrica - e de pessoas. $O$ teatro, como gênero, quando abandona os edifícios prepostos, não encontra espaço na cidade-espetáculo: não tem por que sua fruição gratuita ser inserida na cartografia de pontos de compra e venda (shopping centers, setores urbanos) que disciplina o uso da metrópole. Diante da vigência deste regime de visibilidade, nossas táticas de intervenção visam infiltrar o espetáculo da cidade com formas de experiência dotadas de valor insurrecional, isto é, capazes de rasgar o tecido da praça e afetar a percepção que o cidadão, um espectador involuntário que por ali passa, tem das disciplinas urbanas e de sua atuação nelas. Entendemos por "afetar" a ação de suscitar estranhamento, atrito e encarar o risco de qualquer reação por parte dos transeuntes, caso, ao passo que ocupam aquele território disciplinar, mecanicamente se assumam como fruto disciplinado dele. Tais alteração de estado "afetam" em modo diferente a experiência de ver algo preparado para ser visto: inesperadamente se vê com novos olhos, olhos de viajante, aquilo que, de tanto ver, se julgava óbvio. É um choque, uma expe- 
riência perceptiva "autêntica" (BENJAMIN, 1987). Ao cidadão, convocado em qualidade de especialista do cotidiano, pode ocorrer a vontade de engajar-se na produção de uma dramaturgia (falas, figuras, ações) simultânea e também sucessiva, residual (dúvidas, desconcertos e observações que levariam para o seu próximo destino), provocada pelo que o "afeta". No decorrer do acontecimento na praça, tentamos absorver todas as falas - inclusive os protestos e dissentimentos - de modo que os espectadores reconheçam, no fantasmagórico acontecimento que ocupa aquele lugar e tempo ordinários, a resultante de uma ação coletiva em que pese sua função criativa. O dissenso (mesmo a interdição, por parte de alguém que se julgue normativo ou incomodado por aquela interrupção da ordem) cria um nexo isonômico como maneira de encontro e aprendizagem coletiva. A comunidade temporária ali presente lida com a produção de um "comum" que não anula as diferenças, mas negocia uma linguagem para expressá-las. A forma que abona a disponibilidade das pessoas para negociar sua participação autoral é uma dramaturgia aberta na qual falas surgem e são absorvidas, desconsiderando categorias hierárquicas de autoria, legitimidade e competência. São amplos os questionamentos do Kublai ao adentrar a praça como um entre os outros mendigos, ou seja, mantendo sua atuação focada na presença mais realista possível:

O que é a vida? O que é amor? O que é o dinheiro? O que é propriedade? O que é a guerra? O que é a nação? O que é a favela? O que é o trabalho? O que é realidade? O que é a pobreza? O que é comunidade? O que é o Brasil? O que é o futuro? O que é a saúde? O que é o prazer? O que é o medo? O que quer o povo? O que o povo quer? O povo quer o progresso? O povo quer a prosperidade? O povo tem a prosperidade? ${ }^{4}$

A proliferação de respostas e comentários instala uma deriva produzida pelos transeuntes em sua andança pela praça, ora respondendo, ora repetindo, ora rebatendo a falação contínua do morador de rua que também deambula. Dá nisso:

Todas as coisas são iguais? Alguma coisa tem algum valor? Você é pobre? É justo você ser pobre? Você acha que deveria ganhar mais? É

4 Inspirados na sequência de gritos de Paradise now, montagem histórica da companhia de teatro Living Theatre (Avignon, julho de 1968). 
justo matar em algum caso? É justo matar alguém para defender a sua propriedade? É justo prender alguém porque fez algo ilegal? É justo expulsar alguém da sua casa para construir uma ponte no lugar? Você mente? Isso importa? Quantas vezes por dia? Você acha que é preciso mentir para avançar neste mundo? Você está satisfeito? Deus é brasileiro? Você é brasileiro? O que significa ser brasileiro? Este é o país do futuro? Você acredita no futuro da nação? Isso aqui é arte? Você gosta de arte? Importa gostar de arte? Importa ler? As pessoas que gostam de arte são diferentes das que não se importam? Você se acha diferente dos outros? A arte dá respostas? Você tem uma pergunta? Você vai ao teatro? Vai a concertos, inaugurações, lançamentos? Você vai para não se sentir sozinho? Vai para saber se alguém respondeu alguma pergunta? Vai para descobrir a verdade? A verdade existe? Os jornais dizem a verdade? Artistas em geral dizem a verdade? Jornais mentem? Deliberadamente? Atores e artistas mentem? Deliberadamente? Todas as coisas são iguais? Tanto faz? De que estamos falando?

A proliferação do texto, na forma de troca indisciplinada de discursos, se propõe como experiência de partilha de um "comum" no qual o indivíduo se subjetiva enfatizando sua diferença no seio de uma comunidade capaz de assumir visões heterônomas de mundo, até mesmo pontos de vista (como a do mendigo) tão periféricas que sabotam qualquer critério de centralidade e normalidade (ver BAKHTIM, 1993). Já inquietar, contagiar, deixar rastos seriam resultados estéticos desejáveis, pois, irrompendo no "comum" dado como ordenado, a arte expõe, pelo contrário, como ele estivesse em disputa. Pode a arte estimular aquela comunidade temporária a renegociar os mecanismos da partilha do "comum", ou seja, a se emancipar, mesmo que de modo efêmero (RANCIÈRE, 2012a) dos sistemas que a normatizam?

Uma tática para alimentar tais condições de emancipação do "comum" consiste na manutenção do caráter transitório, imprevisto e inusitado da intervenção na praça, contrariando a tendência de que a obra, uma vez reconhecida como produção ficcional, se instale na ordem formal do espetáculo, com sua distribuição confiável de tarefas e expectativas. Ao contrário, a categoria do choque, ou seja, da irrupção de algo estranho no lugar e no tempo familiar, mantém os transeuntes no estado de alerta de estarem presenciando, assistindo e participando por acaso e involuntariamente aos acontecimentos conflitantes daquele "comum" dos quais são também produtores. Por isso, mantemos a 
ação de "ligar" as instalações a cargo do imperador-mendigo, como um movimento não marcado, aleatório e variável em seus tempos e locais inesperados pelos próprios atores. A rota não é premeditada, como normalmente acontece no teatro de rua, mirando efeitos cenográficos e a maior acumulação de público, mas improvisada, buscando "afetar" a praça com o máximo atrito possível naquele momento - ou após a interrupção do que for. O movimento deambulatório do imperador-mendigo desenha uma linha de fuga no espaço e no tempo que desmonta qualquer expectativa representativa e faz desistir os transeuntes eventualmente acomodados na função-espectador. Para potenciar o efeito de estranhamento, as vozes dos atores são emitidas por um sistema de amplificação montado no carrinho que o imperador-mendigo carrega, dessa forma, quando se afasta, a voz separa-se do emissor e contamina outros cantos da praça, atingindo transeuntes sem a menor expectativa.

Dramaturgia interativa e fuga do espetáculo são táticas contra hegemônicas que, ao passo que sabotam a função-espectador, também destituem o ator de sua função autoral exclusiva. Parece necessário, de fato, manter o anonimato (sem cartaz, sem divulgação, sem folheto e sem agradecimentos), pois tal condição questiona o próprio estatuto de obra, normalmente arvorada na legitimidade dada pela autoria e pela promoção em mídias. $\mathrm{O}$ imperador-mendigo carrega consigo uma cópia do livro de Calvino, que usa para ler nas interrupções e fornecer informações a quem perguntar. Desse modo, enquanto esclarece ser um leitor e cita sua poderosa fonte literária, também mina o conceito de propriedade intelectual já que, nos trajes do mendigo, mesmo tomando a palavra com tamanha potência, ele não seria normalmente autorizado a falar nem, por consequência, seria ouvido. O imperador-mendigo representa o ponto de vista do indivíduo nem consumidor nem commodity da indústria cultural, aquele que, mesmo vendo tudo, permanece invisível porque não participa da cidade que se põe à mostra e se vende. Dramatizando o sentido de tal exclusão, sua presença polifônica escancara a in-visibilidade de outros moradores da praça, excluídos ou minimamente incluídos na partilha do "comum" por viverem às margens dos aparelhos de exposição e consumo (RANCIĖRE, 2012a e 2012b). Provocados pelo acontecimento, outros mendigos na praça passam a se assumir como produtores de imagens e falas, adquirindo visibilidade, voz e uma presença que se impõe, 
repercute o efeito de choque e suspende, naquela comunidade temporária, qualquer marco exclusivo.

Reflexões e reflexos de um fluxo em torno de um desvio, obras como táticas de busca daquilo que, "no meio do inferno, não é inferno para abrir-lhe espaço e fazer com que dure". Não tem como negar a pulsão utópica que move este desvio, que de poético se faz estético-político: instalar no espaço público o lugar agregador do acontecer da arte, como experiência autêntica que se passa aqui, irrompendo no tempo presente e podendo transformar os modos da vida coletiva e da partilha do que é "comum".

Pois bem, diria que na rota dessa viagem a cidade da utopia não aparece. As imagens mais simples de cidades que surgem são rarefeitas, filiformes, como se nossa imaginação otimista, hoje, não pudesse ser senão abstrata, recusando toda imagem reconhecível. Houve um momento em que depois de ter conhecido o escultor Fausto Melotti, um dos primeiros artistas abstratos italianos, que só em sua velhice foi redescoberto e avaliado segundo seu mérito, me veio a ideia de escrever cidades sutis como suas esculturas: cidades como teias de aranha. Em suma, há uma zona em meu livro que tende em direção a um ideal de leveza; não saberia dizer nada mais. (CALVINO, 1972)

\section{Referências bibliográficas}

BAKHTIM, M. Estética da criação verbal. São Paulo: Martins Fontes, 1993.

BENJAMIN, W. Baudelaire, um lírico no auge do capitalismo. São Paulo: Brasiliense, 1987.

Magia e técnica, arte e política. São Paulo: Brasiliense, 1985.

BEY, H. TAZ: zona autônoma temporária. Paris: 1969. Disponível em: <http://www. mom.arq.ufmg.br/mom/arq_interface/4a_aula/Hakim_Bey_TAZ.pdf>.

BOAL, A. O Teatro do Oprimido e outras poéticas políticas. Rio de Janeiro: Civilização Brasileira, 2005.

CANCLINI, N, G. Culturas híbridas. São Paulo: Edusp, 1997.

CALVINO, I. Seis propostas para o próximo milênio. São Paulo: Companhia das Letras, 1990.

Sfogliando l'atlante (colloquio com l'autore). Entrevista concedida para a revista L'Espresso, Roma, n.45, 5 nov. 1972.

Cidades invisíveis, Turim: Einaudi, 1970. Disponível em: <moodle.up.pt/ pluginfile.php/21840/course/section/5603/italo-calvino-as-cidades-invisiveis.pdf>. 
DEBORD, G. A sociedade do espetáculo. Paris: Buchet, 1967. Disponível em: <http://www.ebooksbrasil.org/adobeebook/socespetaculo.pdf $>$.

DE CERTEAU, M. A invenção do cotidiano: artes de fazer. Petrópolis: Vozes, 1998.

FOUCAULT, M. Estética: literatura e pintura, música e cinema. Rio de Janeiro: Forense Universitária, 2009.

INTERNACIONAL SITUACIONISTA. Apologia da deriva: escritos sobre a cidade. Rio de Janeiro: Casa da Palavra, 2003.

LEMOINE, S. Artivisme: art, action politique et résistance culturelle. Paris: Éditions Alternatives, 2010.

RANCIÈRE, J. A partilha do sensível: estética e política. São Paulo: Martins Fontes, 2012a.

O espectador emancipado. São Paulo: Martins Fontes, 2012b.

Recebido em 28/02/2017

Aprovado em 02/05/2017

Publicado em 17/07/2017 